\title{
Numerical Processing and Calculation Deficits in Alzheimer's Disease
}

\author{
Ju Yeon Kimª, HyangHee Kim, ${ }^{\mathrm{a}, \mathrm{b}}$, Ji Hye Yoon', Sung-Rae Cho ${ }^{\mathrm{b}}$ \\ ${ }^{a}$ Graduate Program in Speech and Language Pathology, Yonsei University, Seoul, Korea \\ ${ }^{b}$ Department of Rehabilitation Medicine and Research Institute of Rehabilitation Medicine, Yonsei University College of Medicine, Seoul, Korea \\ 'Department of Speech Pathology and Audiology, Audiology \& Speech Pathology Research Institute, Hallym University, Chuncheon, Korea
}

\author{
Correspondence: HyangHee Kim, PhD \\ Graduate Program in Speech and Language \\ Pathology, Yonsei University, 50-1 Yonsei-ro, \\ Seodaemun-gu, Seoul 03722, Korea \\ Tel: +82-2-2228-3900 \\ Fax: +82-2-2227-7984 \\ E-mail: h.kim@yonsei.ac.kr
}

Received: January 5, 2017

Revised: February 13, 2017

Accepted: February 15, 2017

This paper was summarized from the master's thesis of the first author (2016).

The partial of this paper was presented in the 2016 Fall Conference of the Korean Dementia Association (November 12, 2016).

\begin{abstract}
Objectives: Despite patients with mild dementia's capacity for independent living, they still have difficulty dealing with number processing and calculation due to continued cognitive deterioration. Methods: This study used number processing and calculation tasks with number notation. The subjects of the study were comprised of two groups, an Alzheimer's disease (AD) group $(N=16)$ and a healthy elderly group $(N=16)$. The study compared the error rates and error types in number processing and calculation between the two groups. Results: First, the AD group showed significantly higher errors in number production, number dictation, number reading and transcoding to verbal numerals compared to the control group. The $A D$ group presented more diverse error types in number processing. Both groups had the highest error rates in syntactic errors. Second, the AD group demonstrated remarkably higher errors than the control group in subtraction and multiplication. In addition, the $A D$ group showed higher diversity than the control group in calculation error types. Arithmetic rule errors and factual errors were the two most frequent errors for both groups. Third, there was a double dissociation between number processing and calculation. Conclusion: This study is significant in that it dealt with a detailed analysis of number processing, specifically number transcoding to verbal numerals.
\end{abstract}

Keywords: Alzheimer's disease, Number processing, Number transcoding, Calculation, Arabic numeral, Verbal numeral 숫자(number)는 크기, 양, 순서 등을 나타내는 개념으로 전 세계 공통적으로 아라비아 숫자(Arabic numeral, 예: 1, 2,3 등) 기호로 표현하거나, 각 나라의 언어 숫자(verbal numeral, 예: 일, 이, 삼 등) 로 다르게 명기될 수 있다. 언어는 음소가 모여 음절이 되고, 음절이 모여 의미 단어가 되는 반면, 숫자는 각각이 독립된 기호로서 의미 를 가질 수 있다. 따라서 언어와 숫자는 다른 인지 영역을 분담하고 있을 것으로 추정된다(Kim, Kim, \& Na, 1997). 숫자 처리와 계산에 대한 처리 모델은 대표적으로 맥클로스키 모형(McCloskey, 1992) 을 들 수 있는데, 숫자 처리는 숫자 이해, 숫자 산출, 의미적 표상으 로 구성되며, 계산은 산술 사실 지식, 개념 지식, 절차 지식으로 구 성된다(Kim \& Shin, 2008). 숫자를 표기하는 방법에는 수를 말로 나타내는 명수법(예: 일, 이, 삼 등; 하나, 둘, 셋 등)과수를 기호로 나 타내는 기수법(예: 1, 2, 3 등)이 있다(Chae, 2001). 숫자 읽기에 있어
서 고유어 수사(예: 하나, 둘, 셋 등)와 한자어 수사(예: 일, 이, 삼 등) 를 병용할 수 있는데, '99'까지는 고유어('아흔아홉’)와 한자어('구 십구') 중에 택일하여 사용하나, '100'부터는 한자어만으로(예: ' 101 ' $\rightarrow$ '백일') 혹은 고유어와 한자어를 병행(예: ‘ 101 '’ 백하나')하기도 한 다(Yu, 1999).

숫자 처리 및 계산상 장애를 보이는 환자군은 여럿(예: 실어증, 치 매, 파킨슨병 등) 보고 되고 있는데(Cappelletti, Butterworth, \& Kopelman, 2012; Girelli \& Delazer, 2001; Halpern, McMillan, Moore, Dennis, \& Grossman, 2003; Rosca, 2010; Zamarian et al., 2006), 이 들 중 치매는 점진적인 퇴행성 뇌손상으로 인하여 착어증(paraphasia), 반향어(echolalia), 실어증, 함구증(mutism)등 다양한 언어장 애를 동반한다(Kim, Sim, \& Kwon, 2003). 치매의 원인질환으로 약 70-80여 가지가 알려져 있지만, 그 중에서 알츠하이머성 치매(AD) 
는 가장 흔하다(Kim, Kim, Namkoong, Kim, \& Kim, 2006). AD가 숫자 처리에 관여하는 측두엽과 두정엽의 혈류 및 대사 감소로 인 해 발병한다는 것을 고려하면, 치매 초기 단계에서 숫자와 관련된 장애가 발생할 수 있음을 예상할 수 있다(Deloche et al., 1995; Girelli \& Delazer, 2001; Hirono et al., 1998; Kessler \& Kalbe, 1996; Park, Jang, Baek, Kim, \& Kim, 2013; Rickard et al., 2000; Della Sala, Gentileschi, Gray, \& Spinnler, 2000; Thioux, Ivanoiu, Turconi, \& Seron, 1999; Vansteensel et al., 2014).

숫자 처리에서 $\mathrm{AD}$ 는 크기 비교(magnitude comparison)과제 중 아라비아 숫자 비교 과제보다 구어 숫자 비교 과제에서 오류율이 높았다(Kessler \& Kalbe, 1996). 숫자 받아쓰기에서는 정상군보다 오류율이 높고 또 다양한 오류 유형이 나타났으며, 아라비아 숫자 읽기와 아라비아 숫자 받아쓰기에서는 구문적 오류가 가장 높았 다. 아라비아 숫자를 구어 숫자로 변환하는 과제에서는 특정 코드 (code, 아라비아 숫자 또는 언어 숫자)가 반복되거나 일부만 반복되 는 방해 오류와 보속 오류가 정상군보다 유의하게 높았다(Kessler \& Kalbe, 1996; Della Sala et al., 2000; Tegnér \& Nybäck, 1990; Thioux et al., 1999). 여기서, 숫자 변환이란 아라비아 숫자를 말로 표현 되는 숫자로 바꾸거나 또는 말로 표현되는 숫자를 아라비아 숫자로 변형시키는 과정이다. 계산에서 경도 $\mathrm{AD}$ 는 한 자릿수와 여러 자릿 수로 구성된 덧셈과 뺄셈, 한 자릿수 나눗셈 능력이 유지되는 편이 었고, 오류 유형은 경도 및 중등도 $\mathrm{AD}$ 모두 연산 대치 오류와 숫자 위치 오류가 가장 많았다(Martin et al., 2003). 한편 산술 사실 지식 과 절차 지식 그리고 숫자 처리와 계산 간에 이중 해리(double dissociation)가 있었고(Kaufmann et al., 2002), 몇 명의 경도 $\mathrm{AD}$ 는 숫 자 처리 중 숫자 이해와 숫자 산출 간에도 해리가 있었다(Deloche et al., 1995).

그런데, 선행연구들에서 밝혀진 $\mathrm{AD}$ 의 숫자 처리 및 계산 장애 중, 한국어에서의 고유어와 한자어의 숫자 처리는 연구된 바가 없 으므로, 본 연구의 목적은 알츠하이머성 치매 환자군을 일반 노인 군과 비교하여 숫자 처리 및 계산 수행력에서 오류율과 오류 유형 상에 어떠한 차이가 있는지에 두었다.

\section{연구 방법}

\section{연구 대상}

환자군은 서울 소재 치매지원센터, 경기 및 부산 소재 노인전문 요양병원에서 다음의 조건을 만족하는 16 명을 선정하였다. (1) 신경 과 또는 정신과 전문의가 신경심리학적 평가를 하여 $\mathrm{AD}$ 로 진단받 고, (2) 전반적퇴화척도(Global Deterioration Scale, GDS)에서 3점
Table 1. Demographic information

\begin{tabular}{lcccc}
\hline & $\begin{array}{c}\text { AD group } \\
(\mathrm{N}=16)\end{array}$ & $\begin{array}{c}\text { Control group } \\
(\mathrm{N}=16)\end{array}$ & $t$ & $p$-value \\
\hline Age (yr) & $79.4 \pm 3.9$ & $77.1 \pm 5.1$ & 1.450 & .158 \\
Education (yr) & $8.2 \pm 2.7$ & $8.6 \pm 2.7$ & -.461 & .648 \\
K-MMSE & $18.9 \pm 2.8$ & $27.8 \pm 1.3$ & -11.301 & $<.001^{* * * *}$ \\
SGDS & - & $2.6 \pm 2.0$ & - & - \\
\hline
\end{tabular}

Values are presented as mean $\pm S D$.

$\mathrm{AD}=$ Alzheimer's disease; $\mathrm{K}-\mathrm{MMSE}=$ Korean Mini-Mental State Examination; SGDS $=$ Short Form of Geriatric Depression Scale.

${ }^{* * * *} p<.001$.

(경미한 인지장애) 또는 4점(중등도의 인지장애)으로 평가 받고 (Korean Association for Geriatric Psychiatry, 2003), (3) 한국판 간 이정신상태검사(Korean Mini-Mental State Examination, K-MMSE) 의 읽기, 쓰기 문항에서 만점(2점)을 획득하였으며, (4) 초등학교 졸 업(6년) 이상의 학력을 가진 자로 선정하였다. 정상군은 서울 및 부 산 지역에서 다음의 조건을 만족하는 16 명을 선정하였다. (1) 사전 면담을 실시하여 신경과 및 정신과적 질환 또는 사고력에 영향을 줄 수 있는 질환이 없고, (2) K-MMSE의 규준에 따른 총 점수가 정 상 범주에 속하며(Kang, 2006), 읽기 및 쓰기 문항에서 만점(2점)을 획득하고, (3) 노인우울척도 단축형(Short Form of Geriatric Depression Scale, SGDS)의 규준에 따른 총 점수가 8점 이하(Cho et $\mathrm{al}, 1999)$, (4) 초등학교 졸업(6년) 이상의 학력을 가진 자로 선정하 였다. 두 군의 성비는 남자 8 명, 여자 8 명으로 일치하였다. 대상자군 별 정보는 Table 1에 제시하였다.

\section{연구 과제}

숫자 처리 과제는 숫자 이해, 숫자 산출, 숫자 변환으로 구성하였 으며 연구용 숫자는 Della Sala 등(2000)을 인용하였다. 숫자는 숫 자의 자릿수(일, 십, 백, 천)와 숫자 배열에서 ' 0 '의 위치를 고려하여 선정하였다. 계산 과제는 덧셈, 뺄셈, 곱셈, 나눗셈으로 구성하였고, 초등학교 3학년 수준의 난이도로 일치시켰다(Table 2).

\section{숫자 이해}

숫자 이해 평가는 숫자 크기 비교로 실시하였다. 문항은 두 자릿 수 1 개, 세 자릿수 2 개, 네 자릿수 3 개로 모두 6 개이며, 대상자는 시 각적 자료로 제시된 두 개의 아라비아 숫자(예: 1,2$)$ 를 보고 큰 수를 선택하였다.

\section{숫자 산출}

숫자 산출 평가는 숫자와 관련된 정보를 묻는 질문에 응답하는 
Table 2. Categories and items of each task

\begin{tabular}{ll}
\hline Task & \multicolumn{1}{c}{ Item } \\
\hline Number comprehension & $11 / 13,380 / 308,537 / 720,9018 / 1908,6128 / 6150,4370 / 4106$ \\
Number production & $365,24,1500$, year/month/day \\
Number transcoding & $40,76,314,409,720,3207,8039,4370,2521,6002$ \\
Calculation & $8+8,58+47,604+25,426-108,14-4,320-27,10 \times 3,7 \times 4,47 \times 6,7 \div 1,9 \div 3,24 \div 2$ \\
\hline
\end{tabular}

Table 3. Definitions and examples of error types in number processing

\begin{tabular}{|c|c|c|}
\hline Error type & Definition & Example \\
\hline Syntactic error & Distortion of the number's magnitude. & $365 \rightarrow 3,650$ \\
\hline Lexical error & Faulty production of one or more of the individual elements of a number. & $365 \rightarrow 367$ \\
\hline Perseveration error & Participants continue or repeat writing (speaking) after the cessation of the original stimulus. & $365 \rightarrow 333$ \\
\hline Intrusion error & The original stimulus is repeated or partly repeated, mixed Arabic number and verbal number. & $365 \rightarrow 3$ 백6십오 \\
\hline Mixed error & Multiple errors occurred simultaneously. & $365 \rightarrow$ 3십65 \\
\hline Number separation error & The original stimulus separated each. & $365 \rightarrow 3,6,5$ \\
\hline Copy error & The original stimulus is copied. & $365 \rightarrow 365$ \\
\hline Aphasic error & Breaking the shape of Arabic number. & $6 \rightarrow 0$ \\
\hline Memory error & Participants cannot answer due to semantic memory problem. & No response \\
\hline
\end{tabular}

것이었다. 문항은 모두 4 개로 '일 년의 총 날짜 수(365)', '하루의 총 시간(24)', '돈 세기(1500)', '대상자의 생년월일(예: 1954. 10. 14)'이며 응답은 아라비아 숫자로 쓰는 것이었다.

\section{숫자 변환}

숫자 변환 평가는 3 가지의 하위 과제로 실시하였다. 각 과제는 두 자릿수 2 개, 세 자릿수 3 개, 네 자릿수 5 개로 각 10 개씩 모두 30 개이 었다. 과제의 유형은 청각적으로 제시된 한글 숫자를 아라비아 숫 자로 쓰기(이하, 숫자 받아쓰기), 시각적으로 제시된 아라비아 숫자 를 한글 숫자로 읽기(이하, 숫자 읽기), 시각적으로 제시된 아라비아 숫자를 한글 숫자로 쓰기(이하, 숫자-한글 변환)로 구성하였다.

\section{계산}

계산 평가는 사칙연산(덧셈, 뺄셈, 곱셈, 나눗셈)으로 실시하였 다. 덧셈과 뺄셈은 한 자릿수, 두 자릿수, 세 자릿수로 구성하였고, 곱셈과 나눗셈은 한 자릿수와 두 자릿수로 구성하였다. 네 가지의 연산에는 각 연산에서 적용되는 산술규칙을 포함하였다. 각 연산 의 산술규칙은 덧셈 ' $n+0=n$ ', 뺄셈 ' $n-n=0$ '과 ' $n-0=n$ ', 곱셈 ' $n \times$ $1=n$ '과 ' $\mathrm{n} \times 0=0$ ', 나눗셈 ' $\mathrm{n} \div 1=\mathrm{n}$ 과 ' $\mathrm{n} \div \mathrm{n}=1$ '이 있다.

\section{과제 분석}

과제는 정반응(1점)과 오반응(0점)으로 채점하였고 총 점수는 52점이었다. 오류율은 각 하위 과제 내의 총 문항 수 중 오반응 한 문항에 대한 백분율을 산출하였다. 오류 유형은 각 하위 과제에서
의 오류 빈도로 분석하였다. 모든 오류 유형을 분석한 후, 하위 과제 의 구분 없이 숫자 처리와 계산에서 나타난 총 오류 수 중 각 오류 유형에 대한 백분율을 산출하였다. 숫자 처리 및 계산 오류 유형의 정의와 예시는 Tables 3과 4에 제시하였다(Della Sala et al., 2000; Kessler \& Kalbe, 1996; Martin et al., 2003).

\section{통계 분석}

IBM SPSS (Statistical Package for the Social Science, ver. 23.0) for Window 프로그램을 이용하여 두 집단 간의 숫자 처리 및 계산 에서의 오류율 차이 검정을 모수통계기법인 독립 표본 $t$-검정(independent $t$-test)으로 실시하였다. 통계 분석의 유의수준은 $.05, .01$, $.005, .001$ 로 하였다.

\section{연구 결과}

\section{숫자 처리}

\section{오류율}

숫자 처리 오류율에 있어서 환자군은 정상군보다 숫자 산출 $(p=$ $.048)$, 숫자 받아쓰기 $(p=.002)$, 숫자 읽기 $(p=.008)$, 숫자-한글 변환 $(p<.001)$ 에서 각각 유의하게 높았다.

\section{오류 유형}

숫자 처리에서 환자군은 숫자 이해를 제외하고 총 오류 수 154 개, 총 오류 유형 9 개를 보였다. 정상군도 숫자 이해를 제외하고 총 
Table 4. Definitions and examples of error types in calculation

\begin{tabular}{|c|c|c|}
\hline Error type & Definition & Example \\
\hline Factual error & Incorrect application of an arithmetic table fact. & $5+2=6$ \\
\hline Operation substitution error & Substitution of one arithmetic operation for another. & $7-1=8$ \\
\hline Positional error & Misplaced answers in relation to the problem space or misaligned columns. & - \\
\hline Perseveration error & Participants either copied a digit from one of the operands or wrote the same number multiple times. & $7-1=71$ \\
\hline Zero error & Misuse or misunderstanding of the properties of zero. & $100-4=6$ \\
\hline Arithmetic rule error & Misuse or misunderstanding of the arithmetic rules in each operation. & $3 \times 1=1$ \\
\hline Mixed error & Multiple errors occurred simultaneously. & $7-5=753$ \\
\hline Carrying error & $\begin{array}{l}\text { For addition and multiplication problems that required carrying, participants either omitted the borrowing procedure or } \\
\text { performed in incorrectly. }\end{array}$ & $14+7=11$ \\
\hline Borrowing error & $\begin{array}{l}\text { For subtraction problems that required borrowing, participants either omitted the borrowing procedure or performed in } \\
\text { incorrectly. }\end{array}$ & $10-3=8$ \\
\hline
\end{tabular}

$A D$

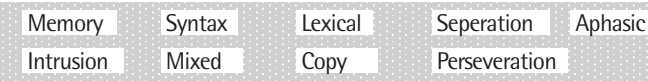

Number production 24 in

Number dictation

Number reading

Transcoding

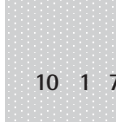

39

(1)

Copy

Control

$\begin{array}{llll}\prec \text { Memory } & \text { "Syntax } & \text { m Lexical } & \square \text { Seperation } \square \text { Aphasic } \\ \approx \text { Intrusion } & \text { || Mixed } & \text { क Copy } & \text { - Perseveration }\end{array}$

Figure 1. Error frequencies of number processing in Alzheimer's disease (AD) group (A) and control group (B).

$A D$

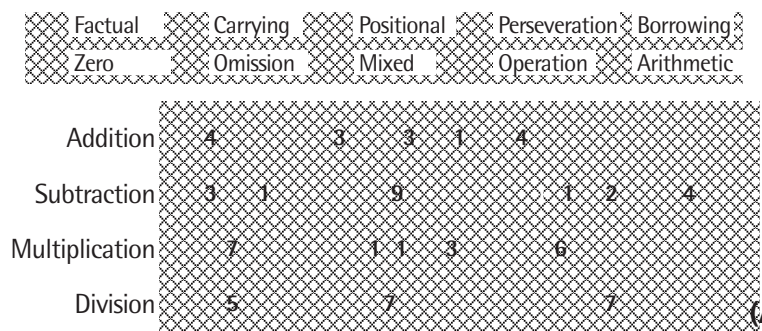

Control

\begin{tabular}{|c|c|c|c|}
\hline Factual & "Carrying & $\therefore$ Positional & $=$ Perseveration $\uparrow$ Borrowing \\
\hline - Zero & Omission & II Mixed & $\square$ Operation \\
\hline
\end{tabular}

Addition 1

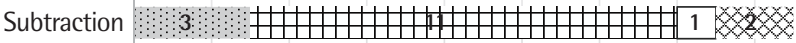

Multiplication $3, \ldots$

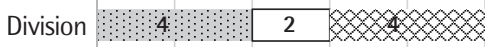

(B)

Figure 2. Error frequencies of calculation in Alzheimer's disease (AD) group (A) and control group (B).

오류 수 37개, 총 오류 유형 6개를 보였다(Figure 1). 환자군은 정상 군보다 총 오류 수가 많았고, 정상군에서 나타나지 않은 기억 오류, 보속 오류, 베껴 쓰기 오류가 있었다. 총 오류 수에서 각 오류 유형에 대한 백분율을 산출한 결과, 환자군에서는 구문 오류(38.3\%), 숫자 분리 오류(18.8\%), 복합 오류(16.2\%), 어휘 오류(10.4\%), 방해 오류 (7.8\%), 자소 오류(5.2\%), 기억 및 베껴 쓰기 오류(각 1.3\%), 보속 오 류(0.6\%)의 순으로 높았다. 정상군에서는 구문 오류(35.1\%), 어휘 오류(21.6\%), 분리 및 방해 오류(각 13.5\%), 자소 오류(10.8\%), 복합 오류(5.4\%)의 순으로 높았다. 두 집단 모두에서 구문 오류가 가장 많았다.

\section{계산}

오류율

계산 오류율에 있어서 환자군은 정상군보다 덧셈 $(p=.003)$ 과 곱 셈 $(p=.040)$ 에서 각각 유의하게 높았다.

\section{오류 유형}

계산에서 환자군은 총 오류 수 73 개, 총 오류 유형 10 개를 보였다 (Figure 2). 정상군은 총 오류 수 35 개, 총 오류 유형 5개가 관찰되었 다. 환자군은 정상군보다 총 오류 수가 많았고, 정상군에서 나타나 지 않은 위치 오류, ‘0’오류, 생략 오류, 복합 오류가 있었다. 오류율 
과 오류 유형에서의 총 오류 수가 다른 것은 오류 유형 분석 시, 산 술규칙 오류를 추가로 분석하였기 때문이다. 총 오류 수에서 각 오 류 유형에 대한 백분율을 산출한 결과, 환자군은 산술규칙 오류 (28.8\%), 사실적 오류(26\%), 대치 오류(13.7\%), 받아내림 오류 (12.3\%), 받아올림 오류(5.5\%), 위치 및 보속 오류(각 4.1\%), 복합 오 류(2.7\%), 생략 및 '0'오류(각 1.4\%)의 순으로 높았다. 정상군은 사 실적 및 받아내림 오류(각 31.4\%), 산술규칙 오류(22.9\%), 대치 오 류(11.4\%), 받아올림 오류(2.9\%)의 순으로 높았다.

\section{논의 및 결론}

$\mathrm{AD}$ 환자들이 숫자 처리 및 계산상의 오류를 보인다는 것은 잘 알 려진 사실이다. 본 연구에서도 그러한 선행연구의 결과와 맥을 같 이 한다. 먼저, 숫자 처리 영역에서의 결과와 그에 따른 논의점을 살 펴보도록 하겠다. 첫째, 숫자 처리 과제에서 환자군은 정상군보다 숫자 산출, 숫자 받아쓰기, 숫자 읽기, 숫자-한글 변환에서 오류율 이 높았다. 숫자 산출 과제에서 오류를 보였다는 뜻은 환자가 실제 로 숫자 자체를 산출하지 못하여 못 썼거나, 혹은 의미 기억의 손상 으로 인하여 자신의 생년월일을 기억해내어 숫자를 써야 하는 과 제 자체를 수행하지 못했다(Norton, Bondi, Salmon, \& Goodglass, 1997)는 뜻이기도 하다. 그러므로 후자의 경우에는 환자에게 '숫자 산출과제 자체를 실시하는 것이 전혀 의미가 없을 수 있다.

둘째, 숫자 처리에서의 오류 유형은 환자군이 정상군보다 다양 한 오류 유형을 보였으며, 특히 숫자 받아쓰기에서 환자군의 구문 적 오류가 매우 높았다. 예컨대, '409 (사백구)'를 '4009 (사백+구)'로 쓰는 오류를 보임으로써 숫자의 배열인 자릿값 이해의 문제가 두드 러졌다. 자릿값 이해(Kang \& Nam, 1999)는 수세기에 대한 개념적 모델, 기호적 표현, 언어적 표현으로 구성되는데, 개념적 모델을 바 탕으로 수를 세는 활동을 통해 말(언어)로 설명하는 것과 아라비아 숫자(기호)로 표현하는 것을 연결하면서 형성되는 것이다. 환자들 은 이 요소 중 개념적 모델에서 기호적 표현으로 변환할 때, 청각적 으로 지각되는 한글 숫자를 글자 그대로 인식한 후, 아라비아 숫자 로 변환 처리하였던 것이다. 만약 ' 409 '에서 ' 0 '의 의미를 정확히 설 명한다면 말로 표현하는 과정에서의 어려움이 없는 것이고, 부정 확하게 설명한다면 개념적 모델을 기호적 표현과 언어적 표현으로 설명하는 과정 모두에서 오류가 발생한 것임을 추정할 수 있다. 그 러나 이 오류가 완전히 자릿값 이해의 오류라면 숫자 이해 과제에 서도 환자군은 정상군보다 유의하게 오류가 높았을 것이지만 숫자 이해는 다른 과제보다 비교적 $\mathrm{AD}$ 환자들의 숫자 처리 능력이 유지 되는 부분이었다. 결국 $\mathrm{AD}$ 환자에서 숫자의 크기를 비교하는 과제
와 숫자 처리 중 숫자 받아쓰기에서 특히 구문적 오류가 많이 나타 난 이유는 기억(memory)의 문제로 귀결된다. 기억은 정보를 등록 하고 보유하여 인출하는 과정인데 유지 시간에 따라 감각 기억, 단 기 기억, 장기 기억으로 분류할 수 있다. 단기 기억 단계로 전환되기 전 감각 기억 단계에서 먼저 기억해야 할 정보가 등록된다(Cho, 2012; Lee, 2000). 숫자 이해에서 시각적으로 제시된 숫자 자극이 사 라지지 않고 환자에게 계속 제공되는 상태이기 때문에 감각 기억 단계에서 과제를 수행할 수 있으므로 과제 난이도가 비교적 쉬운 편인 것이다. 숫자 받아쓰기에서 $\mathrm{AD}$ 환자가 구문적 오류를 보였으 나숫자를 구성하고 있는 수는 같으므로 감각 기억의 등록은 잘 이 루어졌음을 추정할 수 있다. 그러나 감각 기억에서 청각적으로 제 시된 숫자가 저장된 후 단기 기억으로 전환되어 입력된 정보가 즉 시 인출 되어야 하는 과정에서 $\mathrm{AD}$ 환자들은 오류가 발생하는 것이 다. 단기 기억은 작업 기억(working memory)으로도 일컬어지는데 $\mathrm{AD}$ 환자의 작업 기억 저하는 익히 알려진 사실이다(Baddeley, Logie, Bressi, Sala, \& Spinnler, 2007; Graf \& Ohta, 2002; Petersen et al., 1997). 또 단기 기억으로 유입되기 위해서 선택적 주의와 부호화 과정을 거치는데, 부호화 과정에서 시각적, 음성적 또는 언어적(청 각적) 흔적을 이용한다. 그런데 단기 기억은 정보를 언어적으로 기 억하려는 경향이 높기때문에(Oh et al., 1999), 아마도 청각적으로 제시된 숫자 ' 409 '를 언어 '사백구'로 인식하였을 것이며 이를 다시 숫자 ‘4009 (사백구)'로 인출한 것임을 예상할 수 있다.

셋째, 아라비아 숫자를 언어 숫자(즉, 한글 숫자)로 변환하는 과 제인 숫자-한글 변환 과제에서 보인 오류 역시 선행연구 결과와 동 일하게 관찰되었다. 예컨대, 이동 오류(예: 방해 오류 ' 365 ' $\rightarrow$ '삼백 육십 5 ', 보속 오류 ‘365’ $\rightarrow$ ‘333')와 숫자 분리 오류(예: ‘365’ $\rightarrow$ '삼육 오')가 관찰되었는데 이러한 오류는 유럽권에서 행해진 연구에서 도 그 예(예: ' 125 ' $\rightarrow$ 'onetwofive')를 찾아볼 수 있다(Della Sala et al., 2000). 흥미로운 점은 이들 오류가 정상군에서 나타나지 않았 다는 선행연구(Della Sala et al., 2000)와 대조적으로 방해 오류(예: '365' $\rightarrow$ '삼백육십 5 ')가 관찰되었다는 점이다. 이 오류는 특히 치매 환자에서 많이 나타나기 때문에 치매 진단 시 프로토콜로 적용될 수 있다(Della Sala et al., 2000; Kessler \& Kalbe, 1996; Macoir, Audet, Lecomte \& Delisle, 2002; Thioux et al., 1999). 하지만 이러한 숫자-한글 변환 오류는 전두엽 집행기능의 저하(Della Sala et al., 2000), 주의력 저하(Macoir et al., 2002; Tegnér \& Nybäck, 1990), 숫자를 한글로 변환하는 과제에 대한 비친숙도(Macoir et al., 2002) 에 기인할 수 있다. 대뇌피질에서 다중연합피질(multimodal or heteromodal association cortex)의 병변과 함께 전두엽의 대사저하가 주의감독체계(supervisory attentional system)의 손상으로 이어질 
수 있고, 그 결과 이동 오류가 발생하는 것이다(Kessler \& Kalbe, 1996). 다중연합피질은 다양한 감각 양식(multiple sensory modalities)으로부터의 입력(input)을 수용하여 고차 인지 기능(higher order cognitive functions)을 통해 정보를 통합한다. 치매 초기부터 다중연합피질의 손상이 진행되면서 전두엽 집행기능이 저하되고, 결국 숫자 변환의 오류가 발생하게 되는 것이다(Herholz, 1995, 2003; Koss, Ober, Delis, \& Friedland, 1984). 숫자 변환에서의 주의력(attention)은 선택적 주의력과 관련이 있는데, 아라비아 숫자를 언어 숫자로 바꿀 때, 더 자동화되어 있는 아라비아 숫자 사용을 억제하 여 목표 자극인 언어 숫자를 산출하는 것을 의미한다(Macoir et al., 2002; Tegnér \& Nybäck, 1990). 우리는 아라비아 숫자 산출에 익숙하기 때문에 한글 숫자 변환은 더 어렵게 느껴질 수 있다. 따라 서 '숫자-한글 변환' 자체가 숫자 처리 수행력을 알아보는 과제라기 보다 집행 기능이나 주의력을 평가하는 과제라 해도 무리는 아닐 것이다.

다음으로, 계산 영역에서 환자군은 정상군보다 덧셈과 곱셈의 오류율이 높았다. 환자군이 사칙연산에서 오류를 보이는 이유는 계산 과제가 여러 가지 인지기능이 복합적으로 작용하는 어려운 과 제이기 때문이다(Cappelletti et al., 2012). 장기 기억에 저장된 산술 사실은 자동적으로 인출되는 반면 계산은 여러 종류의 인지 기능 들이 일련의 과정을 따라 순서대로 진행되기 때문에 환자군은 각 연산 과정을 모니터링 하는 능력이 떨어져 오류가 발생하는 것이 다. 따라서 뇌의 퇴행이 계속적으로 진행되는 치매의 경우 복잡한 연산을 수행하는데 더욱 어려움이 커질 것이며(Mantovan, Delazer, Ermani, \& Denes, 1999), 이는 결국 초기부터 장기 기억의 서술 기억 손상이 시작되면서 계산의 오류도 증가하게 되는 것과 같은 원리인 것이다.

환자군은 정상군보다 계산의 오류 유형이 더 다양하였다. 고빈 도 오류 유형의 순위는 다르지만 두 집단 모두에서 규칙 오류와 사 실적 오류가 높았다. 첫째, 나눗셈의 ' $\mathrm{n} \div 1=\mathrm{n}$ ' 규칙은 두 집단 모두 에서 오류가 많았지만 나눗셈 연산을 포기한 대상자가 많아 두 군 간의 정확한 차이를 분석할 수 없었다. 둘째, 환자군은 정상군보다 뺄셈의 받아내림 오류가 낮았는데 이는 대부분의 정상군 대상자가 암산으로 과제를 수행하였기 때문인 것으로 보인다. 한편, 앞서 언 급된 숫자 처리에서 오류가 많더라도 계산은 정확하게 수행하거나, 그와는 반대로 계산에서의 오류는 높지만 숫자 처리 오류는 낮은 대상자들이 있었다. 또한 숫자 처리와 계산 사이에서도 이중 해리 가 관찰되었다.

본 연구의 임상적 의의는 아라비아 숫자에 국한되지 않고 숫자 를 표기하는 방법을 아라비아 숫자와 한글 숫자로 구분하여 알츠
하이머성 치매 환자에서 나타나는 숫자 처리와 계산 오류의 특성 을 제시하였으며, 나아가 숫자 처리 과제를 신경인지장애(예: 주의 력 결핍 장애, 집행기능장애 등)의 선별 문항으로 제안하였다는 점 을 들 수 있다. 추후 연구에서는 한국어의 음운 특성을 고려하여 숫 자 자극을 선정하고, 의미 기억이 최소한으로 내포되는 질문을 통 해 치매군의 숫자 산출 능력 연구가 이루어지길 기대해본다. 더불 어 치매의 종류, 중증도 등을 통제하여 후속 연구가 이루어지는 것 이 바람직할수 있다.

\section{REFERENCES}

Baddeley, A., Logie, R., Bressi, S., Sala, S. D., \& Spinnler, H. (1986). Dementia and working memory. The Quarterly Journal of Experimental Psychology, $38,603-618$.

Cappelletti, M., Butterworth, B., \& Kopelman, M. (2012). Numeracy skills in patients with degenerative disorders and focal brain lesions: a neuropsychological investigation. Neuropsychology, 26, 1-19.

Chae, W. (2001). Numerals and their meanings. Korean Semantics, 8, 109-132. Cho, M. J., Bae, J. N., Suh, G. H., Ham, B. J., Kim, J. K., Lee, D. W., \& Kang, M. H. (1999). Validation of geriatric depression scale, Korean version (GDS) in the assessment of DSM-III-R major depression. Journal of Korean Neuropsychiatric Association, 38, 48-63.

Cho, S. J. (2012). Understanding of memory processing. Audiology and Speech Research, 8, 1-8.

Della Sala, S., Gentileschi, V., Gray, C., \& Spinnler, H. (2000). Intrusion errors in numerical transcoding by Alzheimer patients. Neuropsychologia, 38, 768777.

Deloche, G., Mannequin, D., Carlomagno, S., Agniel, A., Dordain, M., Pasquier, F., ... \& Metz-Lutz, M. N. (1995). Calculation and number processing in mild Alzheimer's disease. Journal of Clinical and Experimental Neuropsychology, 17, 634-639.

Girelli, L., \& Delazer, M. (2001). Numerical abilities in dementia. Aphasiolo$g y, 15,681-694$.

Graf, P., \& Ohta, N. (2002). Lifespan development of human memory. Cambridge, MA: MIT Press.

Halpern, C., McMillan, C., Moore, P., Dennis, K., \& Grossman, M. (2003). Calculation impairment in neurodegenerative diseases. Journal of the Neurological Sciences, 208, 31-38.

Herholz, K. (1995). FDG PET and differential diagnosis of dementia. Alzheimer Disease \& Associated Disorders, 9, 6-16. 
Herholz, K. (2003). PET studies in dementia. Annals of Nuclear Medicine, 17, 79-89.

Hirono, N., Mori, E., Ishii, K., Imamura, T., Shimomura, T., Tanimukai, S., ... \& Sasaki, M. (1998). Regional metabolism: associations with dyscalculia in Alzheimer's disease. Journal of Neurology, Neurosurgery \& Psychiatry, 65, 913-916.

Kang, Y. (2006). A normative study of the Korean-Mini Mental State Examination (K-MMSE) in the elderly. Korean Journal of Psychology: General, 25, $1-12$.

Kang, Y., \& Nam, S. (1997). The digits method to improve the number concepts and number senses. Communications of Mathematical Education, 9, 63-72.

Kaufmann, L., Montanes, P., Jacquier, M., Matallana, D., Eibl, G., \& Delazer, M. (2001). About the relationship between basic numerical processing and arithmetics in early Alzheimer's disease: a follow-up study. Brain and Cognition, 48, 398-405.

Kessler, J., \& Kalbe, E. (1996). Written numeral transcoding in patients with Alzheimer's disease. Cortex, 32, 755-761.

Kim, B. G., Kim, H., \& Na, D. L. (1997). A dissociation of number processing between Arabic and Korean numbers: a case study. Journal of the Korean Neurological Association, 15, 186-199.

Kim, E. J., Sim, H. S., \& Kwon, M. S. (2003). A comparison on language processing characteristics in fluent aphasics and dementia of Alzheimer type. Korean Journal of Communication Disorders, 8, 188-208.

Kim, J. W., Kim, H. H., Namkoong, K., Kim, S. J., \& Kim, D. Y. (2006). Spontaneous Speech traits in patients with Alzheimer's disease. Korean Journal of Communication Disorders, 11, 82-98.

Kim, J. B., \& Shin, J. H. (2008). Minds, brains, and learning. Seoul: Hakjisa.

Korean Association for Geriatric Psychiatry. (2003). (Korean) Dementia rating scale. Seoul: Hakjisa.

Koss, E., Ober, B. A., Delis, D. C., \& Friedland, R. P. (1984). The Stroop colorword test: indicator of dementia severity. International Journal of Neuroscience, 24, 53-61.

Lee, K. M. (2000). Patterns of memory impairment. Journal of the Korean Society for Clinical Neurophysiology, 2, 172-178.

Macoir, J., Audet, T., Lecomte, S., \& Delisle, J. (2002). From "Cinquante-Six" to "5quante-Six": the origin of intrusion errors in a patient with probable Alzheimer disease. Cognitive Neuropsychology, 19, 579-601.

Mantovan, M. C., Delazer, M., Ermani, M., \& Denes, G. (1999). The break- down of calculation procedures in Alzheimer's disease. Cortex, 35, 21-38.

Martin, R. C., Annis, S. M., Darling, L. Z., Wadley, V., Harrell, L., \& Marson, D. C. (2003). Loss of calculation abilities in patients with mild and moderate Alzheimer disease. Archives of Neurology, 60, 1585-1589.

McCloskey, M. (1992). Cognitive mechanisms in numerical processing: evidence from acquired dyscalculia. Cognition, 44, 107-157.

Norton, L. E., Bondi, M. W., Salmon, D. P., \& Goodglass, H. (1997). Deterioration of generic knowledge in patients with Alzheimer's disease: evidence from the Number Information Test. Journal of Clinical and Experimental Neuropsychology, 19, 857-866.

Oh, S. J., Kim, Y. H., Kim, C. S., Kim, H. I., Shin, M. S., Yang, G. M., ... , \& Hyeon, J. S. (2010). Human behaviors and psychology. Seoul: Hakjisa.

Park, Y. H., Jang, J. W., Baek, M. J., Kim, J. E., \& Kim, S. (2013). Parietal variant Alzheimer's disease presenting with dyscalculia. Neurological Sciences, $34,779-780$

Petersen, R. C., Smith, G. E., Waring, S. C., Ivnik, R. J., Kokmen, E., \& Tangelos, E. G. (1997). Aging, memory, and mild cognitive impairment. International Psychogeriatrics, 9(S1), 65-69.

Rickard, T. C., Romero, S. G., Basso, G., Wharton, C., Flitman, S., \& Grafman, J. (2000). The calculating brain: an fMRI study. Neuropsychologia, 38, 325335 .

Rosca, E. C. (2010). Acalculia in a patient with severe language disturbances: how do we test it? Cognitive Processing, 11, 371-374.

Tegnér, R., \& Nybäck, H. (1990). “To hundred and twenty4our”: a study of transcoding in dementia. Acta Neurologica Scandinavica, 81, 177-178.

Thioux, M., Ivanoiu IV, A., Turconi, E., \& Seron, X. (1999). Intrusion of the verbal code during the production of Arabic numerals: a single case study in a patient with probable Alzheimer's disease. Cognitive Neuropsychology, $16,749-773$.

Vansteensel, M. J., Bleichner, M. G., Freudenburg, Z. V., Hermes, D., Aarnoutse, E. J., Leijten, F. S., ... \& Ramsey, N. F. (2014). Spatiotemporal characteristics of electrocortical brain activity during mental calculation. Human Brain Mapping, 35, 5903-5920.

Yu, J. W. (1999). Subcategorization of numerals for NLP. Language and Linguistics, 24, 103-110.

Zamarian, L., Visani, P., Delazer, M., Seppi, K., Mair, K. J., Diem, A., ... \& Benke, T. (2006). Parkinson's disease and arithmetics: the role of executive functions. Journal of the Neurological Sciences, 248, 124-130. 


\section{국문초록}

\section{알츠하이머성 치매 환자의 숫자 처리 및 계산 특성}

김주연 ${ }^{1} \cdot$ 김향희 ${ }^{1,2} \cdot$ 윤지혜 ${ }^{3}$ 조성래 ${ }^{2}$

${ }^{1}$ 연세대학교 대학원 언어병리학협동과정, ${ }^{2}$ 연세대학교 의과대학 재활의학교실 및 재활의학연구소, ${ }^{3}$ 한림대학교 언어청각학부

배경 및 목적: 독립적인 생활이 여전히 가능한 치매 환자조차도 인지 기능의 저하로 인해 숫자 처리와 계산에서 어려움을 보일 수 있다. 본 연구에서는 치매 환자군이 정상군에 비해 숫자 처리와 계산 수행 시 오류율과 오류 유형에서 어떤 차이를 보이는지 살펴보았다. 방 법: 알츠하이머성 치매 환자 및 일반 노인 각 16 명씩을 대상으로 숫자 표기법(기수법, 명수법)에 따른 숫자 처리 및 계산 과제를 실시하 여 오류율과 오류 유형을 분석하였다. 결과: 첫째, 숫자 처리의 오류율은 환자군이 정상군보다 숫자 산출, 숫자 받아쓰기, 숫자 읽기, 숫 자-한글 변환에서 높았다. 오류 유형은 환자군이 더 다양하였으며, 두 집단 모두에서 구문적 오류가 가장 많았다. 둘째, 계산의 오류율 은 환자군이 정상군보다 덧셈과 곱셈에서 높았다. 오류 유형 또한 환자군이 다양하였으며, 두 군 모두에서 산술규칙 오류와 사실적 오 류가 가장 많았다. 셋째, 환자군에서 이들 숫자 처리와 계산 간에 이중 해리 현상이 관찰되었다. 논의 및 결론: 숫자 표기법에 따라 분류 된 아라비아 숫자와 한글 숫자를 바탕으로 알츠하이머성 치매 환자에서 나타나는 숫자 처리 및 계산의 오류 양상을 제시하고, 숫자 처 리를 신경인지장애의 선별 문항으로 제안한 점에서 임상적 의의를 찾을 수 있다.

핵심어: 알츠하이머 치매, 숫자 처리, 숫자 변환, 계산, 아라비아 숫자, 한글 숫자

본논문은 제 1 저자의 석사학위논문(2016)의 일부를 발췌한 것임.

본 논문의 일부는 2016 대한치매학회 추계학술대회(2016. 11. 12)에서 발표하였음.

\section{참고문헌}

강연욱(2006). K-MMSE (Korean-Mini Mental State Examination)의 노인 규준 연구. 한국심리학회지: 일반, 25, 1-12.

강영란, 남승인(1997). 수 개념과 감각을 기르기 위한 자리값 지도 방안. 수학교육논문집, 9, 63-72.

김병곤, 김향희, 나덕렬(1997). 한글 숫자와 아라비아 숫자간의 해리: 증례연구. 대한신경과학회지, 15, 186-199.

김은정, 심현섭, 권미선(2003). 유창성실어증과 알츠하이머성치매 환자의 이해능력 특성 비교. 언어청각장애연구, 8, 188-208.

김정완, 김향희, 남궁기, 김세주, 김덕용(2006). 알츠하이머형 치매환자의 발화특성. 언어청각장애연구, 11, 82-98.

김종백, 신종호(2008). 마음, 뇌, 그리고 학습. 서울: 학지사.

대한노인정신의학회(2003). (한국형) 치매 평가검사. 서울: 학지사.

오세진, 김용희, 김청송, 김형일, 신맹식, 양계민, 양돈규, 이요행, 이장한, 이재일, 정태연, 현주석(2010). 인간행동과 심리학. 서울: 학지사.

유재원(1999). 자연어 처리를 위한수사의 하위 범주 분류. 언어와 언어학, 24, 103-110.

이경민(2000). 기억기능장애의 양상. 대한임상신경생리학회지, 2, 172-178.

조맹제, 배재남, 서국희, 함봉진, 김장규, 이동우, 강민희(1999). DSM-III-R의 주요우울증에 대한 한국어판 Geriatric Depression Scale (GDS)의 진단

적 타당성 연구. 신경정신의학, 38, 48-63.

조수진(2012). 기억처리과정의 이해. 청능재활, 8, 1-8.

채완(2001). 수의 표현과 의미. 한국어의미학회, 8, 109-132. 